\title{
A Sanção da Toleima: em «Marquesa, Porque Eu Serei Marquês"
}

\section{Maria Angélica Seabra Rodrigues Martins}

Em 1861, Machado de Assis publicou em A Marmota uma série de artigos, posteriormente reunidos em Miscelânea $(2,1962)$, na forma de um opúsculo. Sob o título de «Queda que as mulheres têm para os tolos», o Autor define ai sua filosofia acerca do relacionamento homem/mulher onde esta, segundo os ditames da sociedade do século XIX, era apenas um meio utilizado pelo homem, através do contrato matrimonial, para ascender social e politicamente.

Nesse ensaio, Machado de Assis divide os pretendentes em dois tipos de homem: o de «espírito» e o «tolo». Sendo feita sobre essa dicotomia a estruturação em Memórias Póstumas de Brás Cubas $(1,1973)$ dos personagens Brás Cubas e Lobo Neves, no seu relacionamento com Virgília - trio em torno do qual se instala o conflito nuclear do romance - selecionamos o capítulo XLIII «Marquesa, porque eu serei marquês»(1,p.56), transcrito a seguir, onde nos será possível identificar as modalidades, bem como os temas e as figuras utilizadas pelo Autor para definir os papéis temáticos homem de espirito e tolo, que polarizam o relacionamento de Virgília com os dois pretendentes.

Desta perspectiva, o homem de espírito, por exemplo, será definido segundo sua constituição modal (v.g. em termos da tensão entre crer e saber, 
querer e poder, fazer e ser), a partir de sua constituição temática (vitória vs.derrota) e os contomos figurativos (horizontalidade vs. verticalidade, rapidez vs. lentidão, acuidade prática vs. acuidade cognitiva, impetuo-sidade vs.veleidade).

A seguir, transcreveremos o texto a ser analisado:

«Positivamente, era um diabrete Virgilia, um diabrete angélico, se querem, mas era-o, e então... Então apareceu o Lobo Neves, um homem que nâo era mais esbelto que eu, nem mais elegante, nem mais lido, nem mais simpático, e todavia foi quem me arrebatou Virgília e a candidatura, dentro de poucas semanas, com um impeto verdadeiramente cesariano. Não precedeu nenhum despeito; não houve a menor violência de familia. Dutra veio dizer-me, um dia, que esperasse outra aragem, porque a candidatura de Lobo Neves era apoiada por grandes influências. Cedi: tal foi o começo de minha derrota. Uma semana depois, Virgília perguntou ao Lobo Neves, a sorrir, quando seria ele ministro.

- Pela minha vontade, já; pela dos outros, daqui a um ano.

Virgília replicou:

- Promete que algum dia me fará baronesa?

- Marquesa, porque eu serei marquês.

Desde então fiquei perdido. Virgília comparou a águia e o pavão, $e$ elegeu a águia, deixando o pavão com seu espanto, o seu despeito, e três ou quatro beijos que lhe dera. Talvez cinco beijos; mas dez que fossem não queria dizer coisa nenhuma. O lábio do homem não é como a pata do cavalo de Atila, que esterilizava o solo em que batia; é justamente o contrário.» $(1$, p.56).

Os valores, no texto, para Lobo Neves e Brás Cubas parecem não funcionar na mesma hierarquia; pois, se para o primeiro, o narrador onipresente sugere ser Virgília um meio que the proporcionaria ascensão político-social (embora indiretamente também o fosse para si - «a candidatura de Lobo Neves era apoiada por grandes influências», "me arrebatou Virgília e a candidatura, dentro de poucas semanas», "Marquesa, porque eu serei marquês»; para o segundo, a moça aparece revestida de uma conotação carinhosa que, neste 
capítulo-texto, fornece ao leitor a impressāo de um Brás Cubas enamorado, para quem a candidatura é um objeto secundário: «diabrete angélico", «fiquei perdido", "o lábio do homem não é como o cavalo de Átila, que esterilizava o solo em que batia(...)».

Desta forma, embora os valores pareçam hierarquicamente distintos, $S 1$ (Brás Cubas) e S2 (Lobo Neves) sāo colocados como anti-sujeitos, um em relação ao outro, porque disputam um mesmo objeto (valor, para o primeiro; modal, para o segundo).Se para Brás Cubas, Virgília é uma pessoa a quem está ligado afetivamente, embora também deseje a candidatura, para Lobo Neves a moça é um meio (objeto modal) através do qual obterá mais facilmente a candidatura, seu objeto-valor.

O conceito de intertextualidade possibilita-nos, neste ponto, a confrontação do capítulo XLIII --«Marquesa, porque eu serei marquês»-- $(1, \mathrm{p} .56)$, com o ensaio machadiano "Queda que as mulheres têm para os tolos», onde o Autor define o conceito de mulher, na visāo do «homem de espírito»:

«As mulheres sào para ele entes de mais elevada natureza que a sua, ou pelo menos ele empresta-lhes as próprias idéias, supõe-lhes um coração como oseu, imagina-as capazes, como ele de generosidade, nobreza e grandeza.» (2, p.967).

E sobre a personalidade do «homem de espírito»:

«Naturalmente tímido, exagera mais ao pé delas a sua insuficiência; o sentimento de que lhe falta muito, torna-o desconfiado, indeciso, atormentado.s (2. p.967).

"Respeitoso até a timidez, não ousa exprimir o seu amor em palavras: exala-o por meio de uma näo interrompida série de meigos cuidados, ternos respeitos e atençōes delicadas». (2, p.967).

O mesmo texto onde Machado discorre sobre sua filosofia acerca do relacionamento homem/mulher explica, também, que o utolo» (menos intelectualizado), não possuindo os escrúpulos acima mencionados, é revestido de sangue frio e segurança: 
«Satisfeito de si, nada lhe paralisa a audácia. Mostra a todos que a ama, e solicita com instância provas de amor(...) importuna-a, acompanha-a nas ruas, vigia-a nas igrejas e espia-a nos espetáculos. Arma-lhe laços grosseiros (...) porquanto revela-lhe o instinto, que pela adulação é que se alcançam as mulheres» $(2$, p.967).

"O tolo é um amante sempre contente e tranqüilo. Tem tão robusta confiança nos seus predicados, que antes de ter provas, já mostra a certeza de ser amado.» $(2$, p.968).

"Como não é ele que ama, é ele quem domina. Para vencer uma mulher finge por alguns momentos o excesso de desespero e paixão (...) Logo depois recobra ele a tirania, e logo depois não a abdica mais.» (2, p.969).

«De resto, como nos tolos tudo é superficial e exterior, não éo amor um acontecimento que lhes mude a vida: continuam como antes a dissipá-la nos jogos, nos salöes e nos passeios. » (2, p.967).

Tal confrontaçāo permite-nos traçar um paralelo entre o texto acima mencionado e Memórias Póstumas de Brás Cubas onde Brás é o «homem de espírito» e Lobo Neves o «tolo», insinuaçāo feita pelo próprio narrador, quando classifica o rival como menos intelectualizado - «nem mais lido"-comparando-o a si próprio. Desta forma, deduz-se que Virgília, para Brás Cubas/ homem de espirito, nāo poderia ser um objeto modal, pois seu conceito de mulher era elevado. Lobo Neves/tolo, entretanto, não considerando o amor algo primordial, na verdade utiliza a chance propiciada pelo casamento com a moça para alcançar seu verdadeiro objetivo: a ascensão político-social.

Apesar de Brás Cubas se ver como um portador de qualidades necessárias a um vencedor (esbelto, elegante, simpático,mais lido - este último, o único trą̧o de uma competência adquirida), ele perde, permanecendo como sujeito disjunto do objeto-valor. No percurso do sujeito Brás Cubas nāo ocorre a realização, pois o sujeito de fazer sofre um bloqueio (conflito entre as modalidades do dever/querer e do saber/fazer) o que interfere em sua performance.

Em Lobo Neves sincretizam-se dois papéis actanciais: o de sujeito de estado disjunto do objeto-valor (para quem Virgília funciona como um objetomodal) e o de sujeito de fazer, competente, modalizado segundo um saber- 
fazer, que realiza sua performance (faz-ser) e obtém uma sanção positiva. Seu programa narrativo principal se define a partir de um programa narrativo secundário, de uso - casamento com Virgília - que lhe tornará possível obter seu propósito: a ascensão político-social.

Um outro aspecto digno de nota é aquele ao qual a intertextualidade conduz, explicando uma constante em Machado de Asssis onde o «tolo", além de menos intelectualizado que o «homem de espírito», é também mais impetuoso e detentor de todos os louros:

"Por menos observador e menos experiente que seja, qualquer pessoa reconhece que a toleima é quase sempre um penhor de triunfo.» (2, p.969);

«O tolo não se faz, nasce feito» $(2, p .966)$;

"O tolo é abençoado do céu pelo fato de ser tolo, e é pelo fato de ser tolo, que the vem a certeza de que, qualquer carreira que tome, há de chegar felizmente ao termo» $(2, p .966)$;

«Ignora o que é ser corrido ou desdenhado» (2, p.966);

"O que opor-lhe como obstáculo? É tão enérgico no choque, tão igual nos esforços e tão seguro no resultado!» (2, p. 966);

«Mulher alguma resistiu nunca a um tolo.» $(2$, p.966).

Diante de tal filosofia irônico-pessimista, o homem de espírito/Brás Cubas obviamente seria um perdedor, enquanto o tolo/Lobo Neves, portador da toleima - «um dom, uma graça, um selo divino» - e a quem conviria um pouco de vulgaridade, sempre venceria.

Em "Marquesa, porque eu serei marquês" convém, ainda, observar o jogo semântico efetuado pelo narrador entre Brás Cubas/pavão/perdedor vs. Lobo Neves/águia/vencedor, onde ocorre a sugestão de que o fato de Virgília ter optado pelo segundo é o resultado de uma prova, da qual resulta a conjunção de Lobo Neves com seu objeto-valor (que para ele funciona, antes, como objetomodal), enquanto Brás Cubas fica disjunto de Virgília e da candidatura. 
Uma observação dos traços que caracterizam a águia e o pavão nos irá conduzir a:

' PAVÃo

* Horizontalidade

* Ave terrestre

* Vôos curtos e de pouca altitude

* Beleza

* (Não Marcado)

* Garras impróprias para caçar
ÁGUIA

* Verticalidade

* Ave celeste

* Vôos longos e de grande altitude

* (Não marcado)

* Acuidade

* Garras apropriadas para caçar. 
Em uma relação de contigüidade, os atores são apresentados como:

\begin{tabular}{|l|l|}
\hline BRÁS CUBAS/PAVÃo & LOBO NEVES/ÁGUIA \\
* Elegante & * (Não marcado) \\
* (Não marcado) & * Esperteza \\
* Simpático & * (Não marcado) \\
* Hesitante & * Impetuoso \\
* Esbelto & * (Não marcado) \\
* (Não Marcado) & * Ambição \\
* Mais lido & * Menos lido \\
* (Não marcado). & * Cercado por grandes \\
& influências \\
* Não concretiza seu querer & * O que não cede \\
\hline
\end{tabular}

Apesar de os valores - esbelteza, elegância, simpatia, intelectualidade - coexistirem em Brás Cubas com as modalidades (dever/querer e poder/ saber) este vive um conflito hiperonímico entre o crer e o não-crer, não conseguindo, por isso, chegar à realização, isto é, ao fazer-ser. Fracassa, porque é marcado pela veleidade: não age no sentido de manter a conjunção que 
acredita possuir com o objeto-valor, pois não crê em sua competência, o que concede a Lobo Neves a oportunidade de arrebatar-lhe Virgília e a candidatura.

A expressão "com ímpeto cesariano» confere a «dentro de poucas semanas» um caráter de transformação repentina que, aliado a «arrebatou» e a «águia», evidencia a natureza impetuosa e atuante de Lobo Neves. No diálogo travado entre este e Virgília, entretanto, a impetuosidade da «águia» é suplantada pela perspicácia de sua presa. Aqui ocorre um subprograma narrativo que narra o fazer-querer, isto é, a instauração do sujjeito modalizado segundo um querer/fazer por ação de um sujeito destinador - Virgília - que manipula um destinatário - Lobo Neves - tornando-o mais ambicioso:

- «Promete que algum dia me fará baronesa?

- Marquesa, porque eu serei marquês.»

Neste momento da narrativa em que Lobo Neves desempenha um papel de objeto-modal e Virgília, a função de um sujeito de fazer (realizado), estabelece-se um contrato. Brás Cubas fica, então, disjunto do objeto-valor: «fiquei perdido» $(1, \mathrm{p} .56)$.

A definição de «diabrete angélico», apresentada logo no início do texto, fornece uma pista de que Virgília não se restringirá a um mero objeto (valor, para Brás Cubas; modal para Lobo Neves); mas, no decorrer da narrativa passará a sujeito de fazer competente, que realiza sua performance - fazer Lobo Neves ficar mais ambicioso, através de um jogo de sedução/manipulação.

É patente, na escritura machadiana, a refinada crítica feita pelo Autor à sociedade do século XIX, que relegava a mulher à condiçāo de mero objeto, do qual se servia o homem, mediante o casamento, para ascender social e politicamente. Machado de Assis, entretanto, extrapola, colocando este ser/angélico/ objeto na posição de fazer/diabrete/atuante, que utiliza as próprias regras da sociedade opressora, subjugando seu opressor virtual: o homem, fruto desta sociedade. A mulher, neste caso, é «diabrete» no sentido de um ser imbuído de sagacidade; e em Virgília a acuidade da águia é a característica-chave.

Virgília, o «diabrete angélico», opta por Lobo Neves, pois crê na capacidade do mesmo, que se mostra mais promissor que Brás Cubas, a fim de alcançar seu objetivo de vida: ser poderosa e respeitada dama da nobreza. Logo, o primeiro pretendente, marcado pela veleidade, não poderia servir a seus propósitos ambiciosos, se comparado ao atuante - e de atuação manipulável - Lobo Neves. 
O texto de Machado de Assis confere à mulher, objeto de disputa de dois homens, características de ambos: o diabrete iguala-se em pensamento e inteligência ao homem de espírito, mas o angélico faz com que ela se perca na ambição do tolo.

Assim, embora em «Queda que as mulheres têm para os tolos», Machado de Assis justifique a atitude feminina como fruto da própria sociedade em que foi criadá («Efetivamente o estranho que ler as suas missivas, nada tem a dizer; na mocidade o pai da menina escrevia assim; a própria menina não esperava outra coisa. Todos estão satisfeitos, até os amigos. Que querem mais?» [2, p.971]), no mesmo ensaio o leitor se depara com um outro trecho que parece esclarecer, singularmente, a opção de Virgília:

"Hoje, graças a Deus, a verdade se descobriu: veio a saber-se que as mulheres escolhem com pleno conhecimento do que fazem. Comparam, examinam, pesam, e só sé decidem por um, depois de verificar nêle a preciosa qualidade que procuram. Essa qualidade é... a toleima!» (2, p.966).

\section{REFERENCIAS BIBLIOGRÁFICAS}

(1) ASSIS, J.M.M.de - Memórias Póstumas de Brás Cubas. São Paulo, Editora Ática, 1973 (4 edição).

(2) ASSIS, J.M.M.de - "Queda queas mulheres têm para os tolos", in Miscelānea, Obra Completa. Rio de Janeiro, Ed.José Aguillar, 1962 (vol. III).

(3) BARROS, D.L.P.de - Teoria do discurso. Fundamentos semióticos. São Paulo, Atual Editora, 1988.

(4) CASTELO, J.A. - Machado de Assis - Critica. Rio de Janeiro, Livraria Agir Editora, 1959.

(5) COUTINHO, A. - A Filosofia de Machado de Assis e Outros Ensaios. Rio de Janeiro, Livraria São José, 1959.

(6) DESMEDT, N. E. - Semiótica da narrativa. Trad. Dra. Alice Maria Frias, Coimbra, Livraria Almedina, 1984.

(7) GRUPO DE ENTREVERNNES - Analisis semiotico de los textos Introducción, teoría, práctica. Trad. Ivan Almeida, Madrid, Ediciones Cristiandad, 1982.

(8) PEREIRA, L.M. - Machado de Assis - Estudo crítico e biográfico. Rio de Janeiro, Livraria José Olympio Editora, 1955 (5ª edição). 